\title{
Calf birth weight and its association with calf and cow survivability, disease incidence, reproductive performance, and milk production
}

\author{
T. C. Linden, R. C. Bicalho, ${ }^{1}$ and D. V. Nydam \\ Department of Population Medicine and Diagnostic Sciences, College of Veterinary Medicine, Cornell University, Ithaca, NY 14853
}

\begin{abstract}
The hypothesis was that calf birth weight $(\mathrm{CBW})$ and a cow calf index [CCI; (calf weight/cow height at parturition $) \times 100$ ] would be associated with calf and cow survivability, disease incidence, reproductive performance, and milk production. Data were collected in a prospective cohort study from one commercial dairy milking 2,800 Holsteins in upstate NY from March 2007 to August 2007. Animals were enrolled at parturition until 1,245 calvings were available for analysis. Data consisted of on-farm measurements of morbidity, mortality, and performance, and data were analyzed using a series of multivariable models including ANOVA and time-to-event analysis. A higher $\mathrm{CBW}$ and a higher CCI were associated with greater odds of lameness. Compared with the lowest quartile of CBW, the odds of the dam becoming subsequently lame increased as the CBW quartiles increased from 2 to 4 ; odds ratio $=1.5,2.7,3.6$, respectively. Compared with the lowest quartile of CCI, the odds of the dam becoming subsequently lame increased as the CCI quartiles increased from 2 to 4 ; odds ratio $=4.6,4.7,4.8$, respectively. Assistance during parturition was associated with higher CBW and with higher CCI. Calves born from assisted parturition had significantly higher $\mathrm{CBW}(\mathrm{CBW}=43.7$ $\mathrm{kg})$ and $\mathrm{CCI}(\mathrm{CCI}=31.4)$ compared with calves born from nonassisted parturition $(\mathrm{CBW}=41.5 \mathrm{~kg}$ and $\mathrm{CCI}$ $=29.7$ ). Neither CBW nor the CCI were associated with stillbirth incidence, calf mortality past $12 \mathrm{~h}$ of life, cow reproduction, or cow survival. We concluded that $\mathrm{CBW}$, and especially the ratio of CBW to dam size, can be associated with some downstream effects, e.g., obstetrical assistance, lameness events, and milk production.
\end{abstract}

Key words: dairy, calf, stillbirth, weight

\section{INTRODUCTION}

Few studies have examined the relationship between calf birth weight $(\mathbf{C B W})$ and subsequent cow and calf

Received August 1, 2008.

Accepted February 20, 2009

${ }^{1}$ Corresponding author: rcb28@cornell.edu survivability, disease incidence, reproductive performance, and milk production in dairy cattle. One report indicated that high CBW was associated with increased perinatal calf mortality and dystocia in dairy cattle (Johanson and Berger, 2003). Stillbirths themselves are a large economic loss; Meyer et al. (2001) reported that losses associated with stillbirths were close to $\$ 125$ million/yr. Also, economic losses from stillbirth parturitions include not only the value of the lost calf, but also decreased milk production, reproductive performance, and survivability (Bicalho et al., 2007, 2008a). Sieber et al. (1989) demonstrated that higher CBW was related to increased dystocia. It was estimated that each year about $7 \%$ of Holstein calves in the United States die within $48 \mathrm{~h}$ of birth (Meyer et al., 2000). Moreover, increased CBW was associated with reduced mean daily weight and height gains in calves born from birth to 6 mo (Donovan et al., 1998).

Lombard et al. (2007) reported that calves born from assisted parturitions were not only at higher risk of stillbirth, but for mortality until $30 \mathrm{~d}$ after birth. Another study reported that dystocia cases had negative effects on 305-d milk, fat, and protein yield, fertility, and cow survival (Dematawewa and Berger, 1997). More specifically, Tenhagen et al. (2007) showed that severe dystocia was associated with decreased conception until 200 DIM. A study by Emanuelson et al. (1993) found that stillbirth parturitions resulted in higher risk of retained placentas and metritis. Moreover, severe dystocia was associated with a reduction in milk production of 0.8 $\mathrm{kg} / \mathrm{d}$ for the rest of their lactation when compared with cows that did not have dystocia (Bicalho et al., 2007). Our previous research described stillbirth parturition as having a detrimental effect on milk production in Holstein cattle as well (Bicalho et al., 2008a).

Increased CBW is associated with dystocia, stillbirths, and calf mortality, all of which were associated with lower calf and cow performance, which can lead to economic losses. Furthermore, the relative size of the calf in relation to the dam can play an important role on the detrimental effect of calf size on the dam's subsequent lactation; birth weight and maternal pelvic size are the 2 most important predictors of feto-pelvic disproportion dystocias (Meijering, 1984). For instance, 
a small young heifer could experience dire consequences to the delivery of an unusually large newborn calf; those consequences would not be as evident for a large cow. Therefore, our objectives were to estimate the effects of CBW and cow calf index (CCI) on calf and cow survivability, disease incidence, reproductive performance, and milk production. Our hypothesis was that both CBW and the CCI would be associated with calf and cow survivability, disease incidence, reproductive performance, and milk production.

\section{MATERIALS AND METHODS}

\section{Farm, Animals, and Management}

Data were from a commercial dairy farm located near Ithaca, New York; calvings occurred between March and August 2007. This farm was selected because of its long history of a working relationship with the Ambulatory and Production Medicine Clinic at Cornell University. The farm milked 2,800 Holstein cows 3 times daily in a double 52 milking parlor. Cows were housed in freestall barns bedded with waste paper-pulp and cleaned by automatic scrapers. The cows were fed a TMR consisting of about $55 \%$ forage (corn silage, haylage, and wheat straw) and $45 \%$ concentrate (corn meal, soybean meal, canola, cottonseed, and citrus pulp). The diet was formulated to meet or exceed the NRC nutrient requirements (NRC, 2001) for lactating Holstein cows weighing $650 \mathrm{~kg}$ and producing $45 \mathrm{~kg}$ of $3.5 \%$ FCM. Cows approaching parturition were housed in free stalls bedded with sand and cleaned by skid steers 2 to 3 times daily. Maternity pens were adjacent to the freestall area of the barn, and pack bedded with shredded paper and cleaned once weekly.

Cows approaching parturition and in maternity groups were monitored $24 \mathrm{~h} / \mathrm{d}$ by farm employees. Employees walked the barns at least once hourly, looking for visual signs of parturition (contractions, observation of fetal membranes or feet), and moved cows to the maternity pens upon detection of parturition signs. After parturition, calves were immediately removed from the maternity pens into a heated calf pen. After parturition, farm employees performed a physical examination and a measurement of the height of the dam, which was measured from the floor up to the upper end of the withers. Before the calves were fed colostrum, they were weighed on a digital scale. Farm employees fed $4 \mathrm{~L}$ of colostrum within the first hour of birth by esophageal tube. Stillbirth was defined as calf mortality shortly before, during, or within the first $12 \mathrm{~h}$ after parturition. Calves were transferred twice daily to the calf facility where they were housed in individual pens and fed pasteurized milk twice daily, along with free choice grain and water.

\section{Data Collection and Study Designs}

The design was a prospective cohort study. Cows were enrolled upon parturition. Farm employees measured both $\mathrm{CBW}$ and the height of the dam at calving. Identification numbers for both dam and calf were recorded, as well as calving ease, calf sex, and whether it was a stillbirth or not.

The remaining data were extracted from Dairy Comp 305 (Valley Ag Software, Tulare, CA) into an Excel (Microsoft Corporation, Redmond, WA) spreadsheet; recorded data were entered into a second spreadsheet, and then merged with the table extracted from Dairy Comp 305 using JMP 6.0.2 (SAS Institute Inc., Cary, $\mathrm{NC}$ ). This was repeated to create 3 distinct data tables: the first for survival, disease, and reproductive performance in cows; the second for survival in calves in the first $12 \mathrm{~h}$ and for the next $230 \mathrm{~d}$; and last, a table for milk production.

\section{Statistical Analyses}

Calvings that occurred before $260 \mathrm{~d}$ of gestation were excluded as our objectives were to consider full-term pregnancies and not abortions. A CCI was created to determine if the ratio of calf weight to dam height was as important as calf weight alone. The CCI was calculated by dividing the birth weight by the height of the dam at calving; to facilitate data analysis and interpretation, the index was then re-expressed by multiplying the resulting fraction by 100 (twins were excluded).

Linear regression models for CBW, CCI, and milk were fitted in SAS (SAS Institute Inc.) using the Mixed procedure. Continuous explanatory variables were categorized into quartiles to facilitate analysis and interpretation. The following variables were categorized into their respective quartiles and offered to the model as independent variables; age of dam at freshening (ADAF), and previous days carried calf (PDCC). The following dichotomous variables were offered to the models: assistance during calving (ADC), season of calving (season). Manual backward stepwise variable elimination of predictor variables was used to find the most parsimonious model that explained the most variability in the dependent outcomes. Biologically plausible 2-way interactions between variables that remained in the model at $P<0.10$ were tested. Cow disease and lameness events from the lactation subsequent to enrollment were detected and recorded by farm employees who had extensive training by the study clinicians. Univariate analysis was done between CBW and CCI and the following diseases: displaced abomasum (DA), lameness, mastitis, retained placenta $(\mathbf{R P})$, and metritis. The only disease that was significantly associated with CBW and CCI was lameness. 
Logistic regression models were fit in SAS using the Logistic procedure to examine in detail the association of CBW and CCI and lameness in the subsequent lactation. A descending response level ordering was used to model odds of a lameness event. The variable selection strategy was similar to the one described. Covariates explored included parity, ADAF, ADC, season, and PDCC.

Frequency tables were created to analyze calf survival up to $12 \mathrm{~h}$ old and mortality of calves up to 230 $\mathrm{d}$ of age. The following continuous variables were categorized according to their respective quartiles: CBW, age of the calf, ADAF, PDCC, and CCI. Categorical variables included parity and season of freshening. The association between these predictor variables and stillbirth or survival to $230 \mathrm{~d}$ of age was investigated with the main interest being CBW and CCI. Twinnings (calf rank 5 and 6) were excluded for the remainder of the analyses to facilitate analysis and interpretation. The variable parity was categorized into $1=$ first parity, $2=$ second parity, and $3=$ third parity and greater. Chi-squared tests of homogeneity were performed on all 2-by-2 tables using the Freq procedure in SAS. Logistic regression models were fitted in SAS using the Logistic procedure (with a descending response level ordering) to assess the effect of several independent variables and the odds of stillbirth parturition, calf mortality, and lactating cow lameness. The variable selection strategy was similar to the one described above. Previous days carried calf was forced into the model to account for its known confounding effect.

Repeated measures ANOVA was conducted for milk yield and was fitted using the Mixed procedure in SAS. The following independent variables were categorized and offered to the model: milk test number (1 to 6), CBW (1 to 4), dam height at freshening (DHF), PDCC, CCI, parity, and the dichotomous variables ADC, season, disease from calving, lameness, and mastitis. Rank of calving was reorganized ( 1 to 3 ) to better facilitate data interpretation and analysis. A score of 3 consisted of singleton parturitions that resulted in stillbirths. The monthly milk weights were longitudinally collected (repeated measures); the error term was modeled by imposing a first-order autoregressive covariance structure to appropriately account for the within cow correlation of milk measurements. Previous days carried calf was forced into the model to account for its known confounding effect. Both outcome variables were examined for normality by visual inspection of frequency histograms, and by performing the following goodness of fit tests: Kolmogorov-Smirnov, Cramer-von Mises, and Anderson-Darling tests.
Cow reproduction and survival were analyzed by Cox's proportional hazard using the test proportional hazard regression (TPHREG) procedure in SAS. For the reproductive survival analyses, cows were right censored if not diagnosed pregnant before culling, death, or the end of data collection. For the survival analysis, cows were censored if they were alive by the end of their data collection period; which ranged from 4 to 11 mo according to their enrollment date. The variables offered to the model were parity, CBW, DHF, CCI, season, ADC, DA, RP, metritis, mastitis, lameness, and rank of calving. Variables retained in the model were tested for interactions. Previous days carried calf was forced into the model as a continuous variable to control for its effects. For all models described above, independent variables and their respective interactions were kept in the models when $P<0.10$ in an attempt to reduce the type II error risk while maintaining a stringent type I error risk at $5 \%$.

\section{RESULTS}

\section{Descriptive Statistics}

A total of 1,245 calvings were available for analysis. After the data exclusion criteria were met, 1,138 calvings were utilized in the models. The mean CBW was $42.9 \pm 6.0 \mathrm{~kg}$ (SD) with a range of 18.6 to $62.7 \mathrm{~kg}$. The mean DHF was $139.2 \pm 5.5 \mathrm{~cm}$ with a range of 121 to $155 \mathrm{~cm}$. Cows ranged from 704 to $3,952 \mathrm{~d}$ in age, with a mean of $1,328.4 \pm 531.2 \mathrm{~d}$. The mean PDCC was $279.7 \pm 8.6 \mathrm{~d}$ and ranged from 260 to $298 \mathrm{~d}$. Frequencies of disease incidences were as follows: $3.7 \%$ DA (42 animals), 6.9\% RP (79 animals), 9.8\% metritis (111 animals), $6.2 \%$ lameness (70 animals), $15 \%$ mastitis (171 animals), and $3.4 \%$ dystocia (39 animals). Of the animals, $155(13.6 \%)$ were sold or died after calving. Total calvings occurred at the following frequencies by month, from March to August respectively: 160 calvings (14\%), 171 calvings (15\%), 283 calvings (25\%), 47 calvings (4\%), 240 calvings (21\%), and 237 calvings (21\%).

After twin parturitions were excluded there were 1,076 calvings, of which 31 calves $(2.9 \%)$ were stillbirths. The 31 stillbirths had a mean weight of $40.1 \pm 6.3 \mathrm{~kg}$, and ranged from 27.3 to $51.8 \mathrm{~kg}$. The remaining calves that were born alive had a mean weight of $43.5 \pm 5.7 \mathrm{~kg}$, and ranged from 21.8 to $62.7 \mathrm{~kg}$. Of the calves that were born alive, only 25 died (4.6\%) postpartum, all of which occurred during the summer. The mean weight and age of the calves that died after the stillbirth period was $39.2 \pm 3.9 \mathrm{~kg}$ and $57.2 \pm 14.6 \mathrm{~d}$ in age, whereas the 
Table 1. Adjusted calf birth weight $(\mathrm{CBW})$ by several independent variables ${ }^{1}$

\begin{tabular}{|c|c|c|c|c|}
\hline Variable & $\mathrm{n}$ & Calf weight $(\mathrm{kg})$ & $95 \% \mathrm{CI}^{2}$ & $P$-value \\
\hline$\overline{\operatorname{PDCC}(\mathrm{d})^{2}}$ & & & & $<0.001$ \\
\hline Gestation $<274$ & 247 & 39.8 & $38.6-40.9$ & \\
\hline $274 \leq$ gestation $<278$ & 231 & 41.9 & $42.0-43.0$ & \\
\hline $278 \leq$ gestation $<281$ & 334 & 43.1 & $42.0-44.1$ & \\
\hline Gestation $\geq 281$ & 326 & 45.6 & $44.5-46.7$ & \\
\hline Rank of calving & & & & $<0.001$ \\
\hline Heifer alive & 622 & 43.9 & $42.9-44.9$ & \\
\hline Bull alive & 423 & 46.1 & $45.1-47.0$ & \\
\hline Heifer dead & 18 & 42.3 & $40.0-44.5$ & \\
\hline Bull dead & 13 & 42.4 & $39.9-44.9$ & \\
\hline Twins & 62 & 38.2 & $36.8-39.6$ & \\
\hline Season of calving & & & & $<0.001$ \\
\hline March-May & 614 & 43.2 & $42.2-44.3$ & \\
\hline June-August & 524 & 41.9 & $40.8-43.0$ & \\
\hline Assist during calving & & & & 0.01 \\
\hline Nonassisted & 1,099 & 41.5 & $40.6-42.3$ & \\
\hline Assisted & 39 & 43.7 & $42.1-45.3$ & \\
\hline Lameness & & & & 0.004 \\
\hline Sound & 1,068 & 41.8 & $40.8-42.7$ & \\
\hline Lame & 70 & 43.4 & $42.0-44.8$ & \\
\hline Dam height at freshening $(\mathrm{cm})$ & & & & $<0.001$ \\
\hline Height $<135$ & 224 & 40.7 & $39.5-41.9$ & \\
\hline $135 \leq$ height $<139$ & 339 & 41.9 & $40.7-43.0$ & \\
\hline $139 \leq$ height $<143$ & 268 & 43.5 & $42.4-44.7$ & \\
\hline Height $\geq 143$ & 307 & 44.2 & $43.1-45.2$ & \\
\hline Parity & & & & 0.002 \\
\hline 1 & 459 & 42.0 & $40.9-43.0$ & \\
\hline 2 & 326 & 43.3 & $42.2-44.4$ & \\
\hline 3 & 181 & 42.5 & $41.3-43.7$ & \\
\hline$\geq 4$ & 172 & 42.5 & $41.3-43.7$ & \\
\hline
\end{tabular}

${ }^{1}$ Calvings occurred between March and August of 2008. A total of 1,138 calvings were used in the analysis. Least squares means are from an ANOVA model for the dependent variable CBW (kg) for primiparous cows, which included the following independent variables: dam height at freshening, age of dam at calving, previous days carried calf (PDCC), parity rank of calving, assistance during calving, season of calving, displaced abomasum, lameness, mastitis, retained placenta, and metritis.

${ }^{2} 95 \%$ confidence interval.

animals that survived to the end of the study period had a mean weight and age of $41.6 \pm 5.1 \mathrm{~kg}$ and $135 \pm$ $2.5 \mathrm{~d}$ in age

\section{Calf Birth Weight and CCl models}

Of the variables offered to the CBW model, PDCC, rank of calving, season, ADC, lameness, and parity were retained as significant variables (Table 1). Height at parturition was highly significant for the CBW model; there was a $3.5 \mathrm{~kg}$ increase in birth weight from the lower quartile to the upper quartile of DHF $(P<$ 0.001; Table 1). A positive association between DHF and CBW was demonstrated in a simple linear regression (Figure 1), which had an $\mathrm{R}^{2}$ of 0.16 .

Of the variables offered to the CCI model, PDCC, rank of calving, season, ADC, lameness, and parity were retained as significant variables (Table 2), similarly to the CBW model.

\section{Calf Birth Weight and $\mathrm{CCl}$ as Predictors of Lameness in the Subsequent Lactation}

In a logistic regression model that examined the odds of lameness, CBW was a significant predictor $(P=$ $0.03)$ when the covariates parity and season were retained in the model. Compared with the lowest quartile of CBW, the odds of the dam becoming subsequently lame increased as the CBW quartiles increased from 2 to 4 ; odds ratio $(\mathbf{O R})=1.5,2.7$, and 3.6, respectively. However, the only $95 \%$ confidence interval (CI) interval that did not include 1 was quartile 4 compared with quartile $1 ; 95 \%$ CI OR $=1.3$ to 9.8 .

In a logistic regression model that examined the odds of lameness, CCI was a significant predictor $(P=0.03)$ when the covariates parity and season were retained in the model. Compared with the lowest quartile of CCI, the odds of the dam becoming subsequently lame increased as the CCI quartiles increased from 2 to 4; 


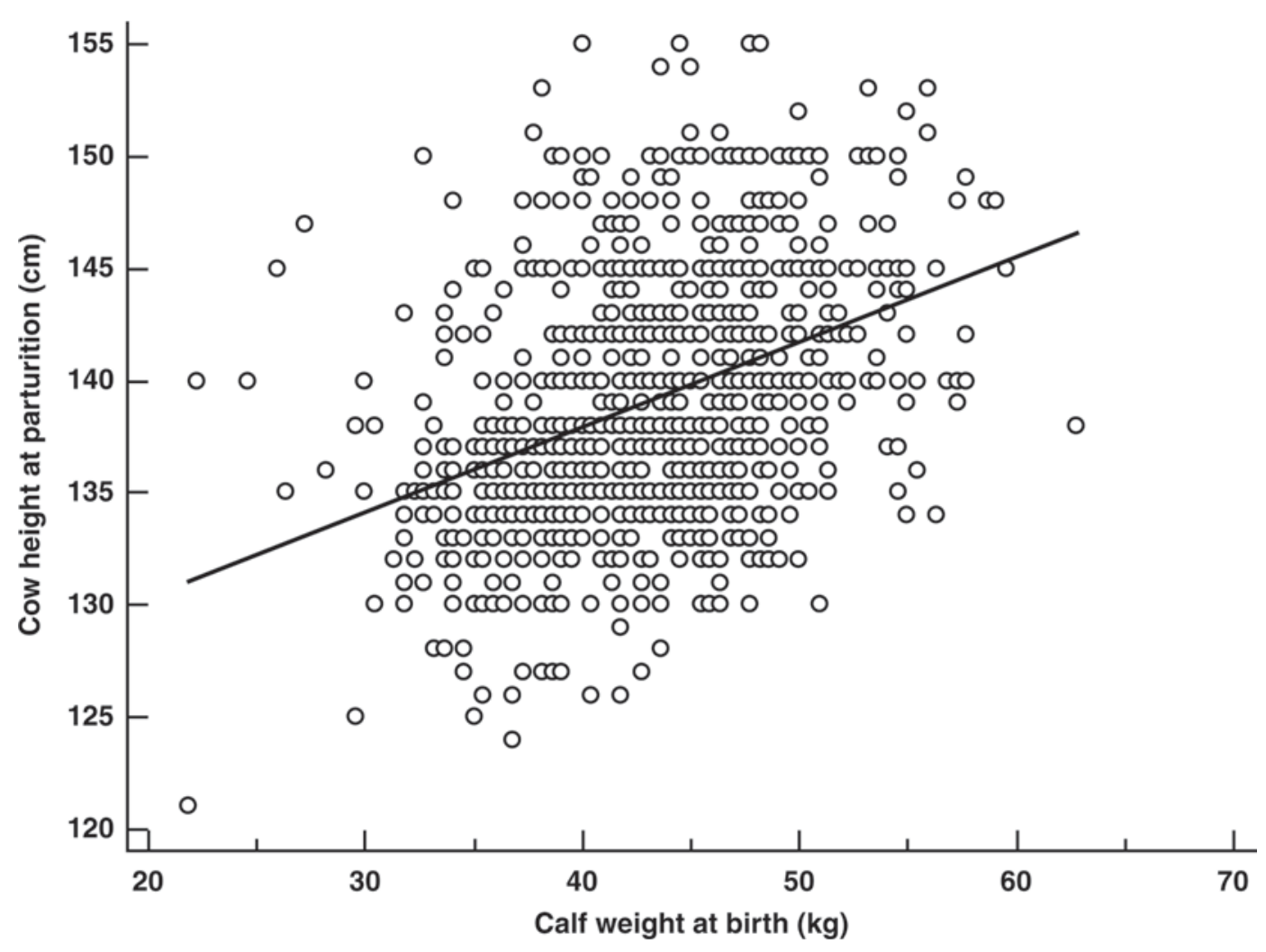

Figure 1. Simple linear regression scatter plot illustrating the linear relationship of cow height at parturition (distance from the floor to the upper end of the withers) and calf birth weight. $R^{2}=0.16$.

$\mathrm{OR}=4.6,4.7$, and 4.8, respectively. In addition to a larger effect than CBW alone, all 95\% CI intervals did not include $1 ; 1.5$ to $14,1.1$ to 10.5 , and 1.6 to 14.4 , respectively.

\section{Stillbirth and Calf Survivability}

There was a tendency for an association between CCI and the odds of stillbirth $(P=0.08)$. Of the variables offered to the stillbirth logistic regression model only CCI was retained (Table 3). Calf birth weight was not a significant predictor of stillbirth.

A second logistic regression model was performed to analyze the risk of death up to $230 \mathrm{~d}$ in age for those heifer calves that were not stillborn. No variables were retained by the model including $\mathrm{CBW}$ and the CCI.

\section{Milk Production}

Of the variables offered to the milk model, the variables DHF, rank of calving, parity, season, mastitis, and test number were significant. Parity, season, mastitis, and test number were highly significant $(P<0.001$; Table 4). Test number showed a typical lactation curve, peaking at a mean milk production of $40.5 \mathrm{~kg}$ at test 2 and 3, and gradually dropping for the rest of the test numbers (Table 4).

\section{Reproductive Performance and Cow Survivability}

After following data exclusion criteria, survival analyses for reproduction and survival were conducted on 1,076 calvings. The distribution of animals among the parity groups were as follows; 451 first-parity animals, 304 second-parity animals, and 321 animals $\geq 3$ parities. A total of 723 animals $(67.2 \%)$ were confirmed pregnant over the period of data collection; 142 cows $(13.2 \%)$ died or were culled during the data collection period.

Parity and season were highly significant $(P<0.001)$ in the reproductive model; the hazard ratio for risk of being detected pregnant was $3.0(95 \% \mathrm{CI}=2.7$ to 3.3$)$ for the spring season versus the summer season; the hazard ratio for being detected pregnant was $1.9(95 \%$ $\mathrm{CI}=1.6$ to 2.1 ) for primiparous cows versus multiparous cows. The variables displaced abomasums, metritis, and mastitis were retained by the model (Table 5). The only variables retained for the survivability model were parity, metritis, and mastitis (Table 6). Neither CBW nor the CCI was significant $(P>0.10)$ for the 
Table 2. Adjusted cow calf indexes (CCI) by several independent variables ${ }^{1}$

\begin{tabular}{|c|c|c|c|c|}
\hline Variable & $\mathrm{n}$ & $\mathrm{CCI}$ & $95 \% \mathrm{CI}^{2}$ & $P$-value \\
\hline $\operatorname{PDCC}(\mathrm{d})$ & & & & $<0.01$ \\
\hline Gestation $<276$ & 247 & 28.5 & $27.7-29.3$ & \\
\hline $276 \leq$ gestation $<279$ & 231 & 30.1 & $29.2-30.9$ & \\
\hline $279 \leq$ gestation $<283$ & 334 & 31.9 & $30.1-31.7$ & \\
\hline Gestation $\geq 283$ & 326 & 32.6 & $31.8-33.4$ & \\
\hline Rank of calving & & & & $<0.01$ \\
\hline Heifer alive & 622 & 31.5 & $30.8-32.2$ & \\
\hline Bull alive & 423 & 33.1 & $32.4-33.8$ & \\
\hline Heifer dead & 18 & 30.3 & $28.7-32.0$ & \\
\hline Bull dead & 13 & 30.3 & $28.5-32.1$ & \\
\hline Twins & 62 & 27.4 & $26.4-28.4$ & \\
\hline Season of calving & & & & $<0.01$ \\
\hline March-May & 614 & 31.0 & $30.3-31.7$ & \\
\hline June-August & 524 & 30.1 & $29.3-30.8$ & \\
\hline Assist during calving & & & & $<0.01$ \\
\hline Nonassisted & 1,099 & 29.7 & $29.0-30.3$ & \\
\hline Assisted & 39 & 31.4 & $30.3-32.5$ & \\
\hline Lameness & & & & 0.01 \\
\hline Sound & 1,068 & 30.0 & $29.4-30.6$ & \\
\hline Lame & 70 & 31.1 & $30.1-32.0$ & \\
\hline Parity & & & & $<0.01$ \\
\hline 1 & 459 & 30.3 & $29.5-31.0$ & \\
\hline 2 & 326 & 31.1 & $30.3-31.9$ & \\
\hline 3 & 181 & 30.4 & $29.6-31.3$ & \\
\hline$\geq 4$ & 172 & 30.3 & $29.4-31.1$ & \\
\hline
\end{tabular}

${ }^{1}$ Calvings occurred between March and August of 2008. A total of 1,138 calvings were used in the analysis. CCI was calculated by dividing the calf weight by the dam height at calving and multiplying by $100[\mathrm{CCI}=$ (calf weight/dam height at calving) $\times 100]$. Least squares means are from an ANOVA model for the dependent variable index (CCI), which included the following independent variables: age of dam at calving, previous days carried calf (PDCC), parity, rank of calving, assistance during calving, season of calving, displaced abomasum, lameness, mastitis, retained placenta, and metritis.

${ }^{2} 95 \%$ confidence interval.

reproduction or cow survival models and were not included in the final model.

\section{DISCUSSION}

Season, rank of calving, and PDCC were significantly associated with both CCI and CBW. Past studies have shown that gestation length and birth weight in cattle are positively associated (Jafar et al., 1950). In our study, DHF was associated with the newborn calf weight. Previous studies demonstrated that larger cows had a tendency to have larger calves compared with smaller cows (Sieber et al., 1989; Swali and Wathes, 2006). Size at birth is an indicator of fetal growth, which is primarily determined by the maternal uterine environment (Swali and Wathes, 2006). Nevertheless, maternal size was positively associated with birth weight; maternal and paternal genotype contributed up to $40 \%$ of the birth weight variation (Swali and Wathes, 2006). Rank of calving was significant for both outcome variables. Bulls born alive averaged a higher mean CBW and CCI; heifers born alive to multiparous animals followed the same pattern. This leaves room for interpretation that there may have been an underly- ing cause for the under-development of the calves that died, whether it be biological (disease) or environmental (nutrition and social hierarchy) effects on the calf and dam. Mean CBW and the CCI were lower for twins than all other categories for both outcome variables and parity groupings, as twins tend to be smaller than singletons (Kertz et al., 1997).

Cows in need of assistance during parturition had increased CBW and CCI, which confirm earlier results that CBW is associated with dystocia (Sieber et al., 1989; Johanson and Berger, 2003). Calf birth weight

Table 3. Results of logistic regression model for risk of stillbirth (dead on arrival or within $12 \mathrm{~h}$ of birth $)^{1}$

\begin{tabular}{lcl}
\hline Variable & Odds ratio & $95 \% \mathrm{CI}^{2}$ \\
\hline CCI quartile & & \\
1 & Referent & Referent \\
2 & 0.34 & $0.12-0.96$ \\
3 & 0.48 & $0.18-1.2$ \\
4 & 0.28 & $0.08-0.93$ \\
\hline
\end{tabular}

${ }^{1}$ The following variables were offered to the model: calf birth weight, dam height at freshening, age in days of the dam, previous days carried calf, cow calf index (CCI), parity, and season of calving.

${ }^{2} 95 \%$ confidence interval. 
LINDEN ET AL.

Table 4. Adjusted daily milk yields $(\mathrm{kg} / \mathrm{d})$ by several independent variables ${ }^{1}$

\begin{tabular}{|c|c|c|c|}
\hline Variable & Milk yield (kg/d) & $95 \% \mathrm{CI}^{2}$ & $P$-value \\
\hline CCI & & & 0.09 \\
\hline CCI $<28.7$ & 36.8 & $35.9-37.7$ & \\
\hline $28.7 \leq \mathrm{CCI}<31.2$ & 37.2 & $36.3-38.1$ & \\
\hline $31.2 \leq \mathrm{CCI}<33.7$ & 37.3 & $36.4-38.2$ & \\
\hline $\mathrm{CCI} \geq 33.7$ & 38.2 & $37.3-39.2$ & \\
\hline Dam height at freshening $(\mathrm{cm})$ & & & 0.01 \\
\hline Height $<135$ & 35.4 & $34.1-36.8$ & \\
\hline $135 \leq$ height $<139$ & 36.2 & $34.9-37.5$ & \\
\hline $139 \leq$ height $<143$ & 37.4 & $36.3-38.5$ & \\
\hline Height $\geq 143$ & 38.3 & $37.1-39.4$ & \\
\hline \multicolumn{4}{|l|}{ Rank of calving } \\
\hline Heifer alive & 37.8 & $37.1-38.5$ & \\
\hline Bull alive & 37.0 & $36.2-37.8$ & \\
\hline Other & 35.8 & $33.2-38.3$ & \\
\hline Parity & & & $<0.01$ \\
\hline 1 & 33.1 & $32.0-34.2$ & \\
\hline 2 & 39.0 & $37.8-40.2$ & \\
\hline$>2$ & 38.4 & $37.1-39.6$ & \\
\hline Season of calving & & & $<0.01$ \\
\hline March-May & 38.5 & $37.5-39.5$ & \\
\hline June-August & 35.1 & $34.0-36.2$ & \\
\hline Mastitis & & & $<0.01$ \\
\hline No mastitis & 38.1 & $37.2-39$ & \\
\hline Mastitis & 35.6 & $34.3-36.9$ & \\
\hline Test number & & & $<0.01$ \\
\hline 1 & 31.1 & $30.1-32.1$ & \\
\hline 2 & 40.5 & $39.5-41.5$ & \\
\hline 3 & 40.5 & $39.5-41.5$ & \\
\hline 4 & 39.4 & $38.3-40.5$ & \\
\hline 5 & 36.0 & $34.9-37.1$ & \\
\hline 6 & 33.6 & $32.3-34.8$ & \\
\hline
\end{tabular}

${ }^{1}$ Calvings occurred between March and August of 2008. A total of 1,076 calvings were used in the analysis. The following independent variables were offered to the repeated measures ANOVA model for the dependent variable mean milk yield: milk test number (1-6), calf birth weight (1-4), dam height at freshening (1-4), previous days carried calf, cow calf index (CCI; $1-4)$, rank of calving (1-3), parity (1-3), assistance during calving (0 or 1 ), season of calving ( 0 or 1$)$, disease from calving ( 0 or 1$)$, lameness ( 0 or 1$)$, and mastitis (0 or 1$)$. Previous days carried calf was forced into the model to account for its known confounding effect.

${ }^{2} 95 \%$ confidence interval.

Table 5. Cox's proportional hazards analysis for risk of pregnancy measured as the calving-to-conception interval $^{1}$

\begin{tabular}{|c|c|c|c|c|c|}
\hline Variable & Parameter estimate & SE & Hazard ratio & $95 \% \mathrm{CI}^{2}$ & $P$-value \\
\hline Parity & & & & & $<0.01$ \\
\hline 1 & 0.62 & 0.1 & 1.9 & $1.6-2.1$ & \\
\hline 2 & 0.05 & 0.2 & 1.1 & $0.7-1.4$ & \\
\hline$>2$ & & Referent & & & \\
\hline Season of calving & & & & & $<0.01$ \\
\hline March-May & 1.1 & 0.2 & 3.0 & $2.7-3.3$ & \\
\hline $\begin{array}{l}\text { June-August } \\
\text { Displaced abomasum (DA) }\end{array}$ & & Referent & & & 00 \\
\hline $\begin{array}{l}\text { Displaced abomasum (DA) } \\
\text { None }\end{array}$ & 1.1 & 0.5 & 3.0 & $2.1-3.9$ & 0.02 \\
\hline DA & & Referent & & & \\
\hline Metritis & & & & & $<0.01$ \\
\hline None & 0.8 & 0.2 & 2.2 & $1.7-2.6$ & \\
\hline Metritis & & Referent & & & \\
\hline Mastitis & & & & & 0.08 \\
\hline None & 0.3 & 0.2 & 1.3 & $1.0-1.6$ & \\
\hline Mastitis & & Referent & & & \\
\hline
\end{tabular}

${ }^{1}$ The following independent variables were offered to the proportional hazards regression model: parity, calf birth weight, height of dam at freshening, cow calf index (CCI), rank of calving, season, assist, displaced abomasum, retained placentas, metritis, mastitis, and lameness. Previous days carried calf was forced into the model to account for its known confounding effect.

${ }^{2} 95 \%$ confidence interval. 
Table 6. Cox's proportional hazards analysis of cow mortality or culling measured as calving-to-cull or death interval $^{1}$

\begin{tabular}{lccccc}
\hline Variable & Parameter estimate & $\mathrm{SE}$ & Hazard ratio & $95 \% \mathrm{CI}^{2}$ & $P$-value \\
\hline Parity & & & & & $<0.01$ \\
1 & Referent & Referent & Referent & Referent & \\
2 & 0.6 & 0.3 & 1.8 & $1.3-2.2$ & \\
$>2$ & 1.3 & 0.2 & 3.5 & $3.1-3.9$ & \\
Metritis & & & & 0.03 \\
None & Referent & Referent & Referent & Referent & \\
Metritis & 0.6 & 0.3 & 1.9 & $1.3-2.4$ & \\
Mastitis & & & & \\
None & Referent & Referent & Referent & Referent & \\
Mastitis & 0.4 & 0.2 & 1.6 & $1.2-1.9$ & \\
\hline
\end{tabular}

${ }^{1}$ The following independent variables were offered to the test proportional hazards regression model: parity, calf birth weight, height of dam at freshening, cow calf index (CCI), rank of calving, season, assist, displaced abomasum, retained placentas, metritis, mastitis, and lameness. Previous days carried calf was forced into the model to account for its known confounding effect.

${ }^{2} 95 \%$ confidence interval.

increased during cooler months in comparison to hotter months; cows had a lower mean CBW and CCI for hotter months. Heat stress in dairy cattle has been associated with reduced DMI (West, 2003), contributing to decreased nutrient consumption, which may result in smaller calves being born during hotter months. This assumption is supported by a study in which CBW increased in cows that were cooled during the dry period (Wolfenson et al., 1988).

Calf birth weight and CCI were positively associated with the odds of lameness in the subsequent lactation. Cows that gave birth to bigger calves and cows with high CCI were more likely to become lame. Previous work reported that changes in the biochemistry and biomechanics in the hoof were the result of parturition with related hormones having a secondary effect on support structures (Knott et al., 2007). Additionally, it was hypothesized that weight gained throughout gestation could increase stress on the hoof wall and subsequently cause lameness (Fullmer, 1960). We found that larger animals coincided with larger mean CBW, suggesting that larger Holstein cows were more likely to became lame than smaller cows. Furthermore, CCI was a better predictor of lameness than CBW indicating that the relationship of dam size to calf size is more predictive of lameness than calf size alone. It is important to emphasize that DHF were positively associated with milk production in the subsequent lactation. High milk production is a risk factor for lameness; lame cows produced $3 \mathrm{~kg}$ of milk/d more than nonlame cows (Bicalho et al. 2008b). Hence, it is possible that CCI is a confounding effect and a cause and effect relationship of CCI and lameness may not exist.

We examined the relationships between CBW or CCI and survival of calves both at parturition and up to $230 \mathrm{~d}$ in age. Our study farm had a stillbirth incidence rate of $2.9 \%$ at the conclusion, which was lower than the $3.7 \%$ stillbirth incidence estimated by the USDA (USDA, 2002). It is important to highlight that this lower incidence of stillbirth parturition could have decreased the statistical power and increased the probability of type II error; the results of stillbirth models are probably conservative. Furthermore, our case definition for stillbirth included calves that were dead at birth or were born alive but were found dead up to $12 \mathrm{~h}$ after parturition because this is the working definition at this dairy because of management movements of newborn calves. The typical case definition of stillbirth parturition includes calf mortality before, during, or within 24 to $48 \mathrm{~h}$ of parturition (Philipsson et al., 1979), partially explaining the lower stillbirth incidence found in our study.

No variables explored were significant for calf mortality post $12 \mathrm{~h}$. Calf mortality rate on the farm during the study period was $4.6 \%$ compared with $8.7 \%$ mortality rate of calves before weaning reported by the USDA (USDA, 2002). Neither CBW nor CCI showed an association with calf survival at parturition or post parturition and were rejected from the model. Again, there may be a chance of a type II error because of the better than average management of milk-fed calves at this dairy compared with average US dairy farms. The ability to better manage calves may mask effects related to the calving period.

Parity was retained in the model and was significant, as primiparous cows typically make less milk than multiparous cows (Meikle et al., 2004). Season was highly significant in the model. A reduction in milk production of $3.4 \mathrm{~kg}$ of milk/d occurred in the months of June through August compared with March through May. Umphrey et al. (2001) reported a partial correlation between milk production and rectal temperature of -0.135 , which can most likely be attributed to a reduction in DMI from heat stress (West, 2003). Mas- 
titis was retained by the model; mean milk production dropped by $2.5 \mathrm{~kg} / \mathrm{d}$ for animals with mastitis versus those without.

We assessed the effect of CBW and CCI on the reproductive performance. Both $\mathrm{CBW}$ and $\mathrm{CCI}$ were rejected from the model. Still, parity and season were highly significant. Heat stress, which would coincide with the months June through August, had adverse effects on reproductive performance in dairy cattle by inducing alterations in follicular dynamics (Wolfenson et al., 1995).

The final analysis of CBW and the CCI was examining any associations with cow survivability. Neither CBW nor the CCI were retained in the model as significant variables; however, parity, metritis, and mastitis were retained. Parity was highly significant, most likely due to higher parity animals leaving the herd because of age-related culling or mortality.

It is important to acknowledge that our study was potentially exposed to several measurement errors because most data were collected on the farm by farm employees. Measurements such as the height of the cow can vary significantly with the depth and softness of the bedding at the maternity pen and the body posture of the cow at the time of the measurement.

\section{CONCLUSIONS}

We concluded that assistance during parturition was associated with higher CBW and with higher CCI. Furthermore, higher CBW and a higher CCI were associated with a higher incidence of lameness in cows' next lactations. Of these 2 potential predictors, CCI was more consistently associated with a higher odds ratio of lameness. Conversely, neither CBW nor the CCI were associated with stillbirth incidence, calf mortality past $12 \mathrm{~h}$ of life, cow reproduction, or cow survival at a type I error risk of less than $5 \%$. In this study CBW and especially the ratio of CBW to dam size can be associated with some downstream effects; for example, obstetrical assistance, lameness events, and milk production.

\section{REFERENCES}

Bicalho, R. C., K. N. Galvao, S. H. Cheong, R. O. Gilbert, L. D. Warnick, and C. L. Guard. 2007. Effect of stillbirths on dam survival and reproduction performance in Holstein dairy cows. J. Dairy Sci. 90:2797-2803.

Bicalho, R. C., K. N. Galvao, L. D. Warnick, and C. L. Guard. 2008a. Stillbirth parturition reduces milk production in Holstein cows. Prev. Vet. Med. 84:112-120.

Bicalho, R. C., L. D. Warnick, and C. L. Guard. 2008b. Strategies to analyze milk losses caused by diseases with potential incidence throughout the lactation: A lameness example. J. Dairy Sci. $91: 2653-2661$

Dematawewa, C. M., and P. J. Berger. 1997. Effect of dystocia on yield, fertility, and cow losses and an economic evaluation of dystocia scores for Holsteins. J. Dairy Sci. 80:754-761.
Donovan, G. A., I. R. Dohoo, D. M. Montgomery, and F. L. Bennett. 1998. Calf and disease factors affecting growth in female Holstein calves in Florida, USA. Prev. Vet. Med. 33:1-10.

Emanuelson, U., P. A. Oltenacu, and Y. T. Grohn. 1993. Nonlinear mixed model analyses of five production disorders of dairy cattle. J. Dairy Sci. 76:2765-2772.

Fullmer, H. M. 1960. A comparative histochemical study of elastic pre-elastic and oxytalan connective tissue fibers. J. Histochem. Cytochem. 8:290-295.

Jafar, S. M., A. B. Chapman, and L. E. Casida. 1950. Causes of variation in length of gestation in dairy cattle. J. Anim. Sci. 9:593-601.

Johanson, J. M., and P. J. Berger. 2003. Birth weight as a predictor of calving ease and perinatal mortality in Holstein cattle. J. Dairy Sci. $86: 3745-3755$.

Kertz, A. F., L. F. Reutzel, B. A. Barton, and R. L. Ely. 1997. Body weight, body condition score, and wither height of prepartum Holstein cows and birth weight and sex of calves by parity: A database and summary. J. Dairy Sci. 80:525-529.

Knott, L., J. F. Tarlton, H. Craft, and A. J. Webster. 2007. Effects of housing, parturition and diet change on the biochemistry and biomechanics of the support structures of the hoof of dairy heifers. Vet. J. 174:277-287.

Lombard, J. E., F. B. Garry, S. M. Tomlinson, and L. P. Garber. 2007. Impacts of dystocia on health and survival of dairy calves. J. Dairy Sci. 90:1751-1760.

Meijering, A. 1984. Dystocia and stillbirth in cattle-A review of causes, relations and implications. Livest. Prod. Sci. 11:143-177.

Meikle, A., M. Kulcsar, Y. Chilliard, H. Febel, C. Delavaud, D Cavestany, and P. Chilibroste. 2004. Effects of parity and body condition at parturition on endocrine and reproductive parameters of the cow. Reproduction 127:727-737.

Meyer, C. L., P. J. Berger, and K. J. Koehler. 2000. Interactions among factors affecting stillbirths in Holstein cattle in the United States. J. Dairy Sci. 83:2657-2663.

Meyer, C. L., P. J. Berger, K. J. Koehler, J. R. Thompson, and C. G. Sattler. 2001. Phenotypic trends in incidence of stillbirth for Holsteins in the United States. J. Dairy Sci. 84:515-523.

NRC. 2001. Nutrient Requirements of Dairy Cattle. 7th rev. ed. National Academy Press, Washington, DC.

Philipsson, J., J. L. Foulley, J. Lederer, T. Liboriussen, and A. Osinga. 1979. Sire evaluation standards and breeding strategies for limiting dystocia and stillbirth. Report of an EEC/EAAP working group. Livest. Prod. Sci. 6:111-127.

Sieber, M., A. E. Freeman, and D. H. Kelley. 1989. Effects of body measurements and weight on calf size and calving difficulty of Holsteins. J. Dairy Sci. 72:2402-2410.

Swali, A., and D. C. Wathes. 2006. Influence of the dam and sire on size at birth and subsequent growth, milk production and fertility in dairy heifers. Theriogenology 66:1173-1184.

Tenhagen, B. A., A. Helmbold, and W. Heuwieser. 2007. Effect of various degrees of dystocia in dairy cattle on calf viability, milk production, fertility and culling. J. Vet. Med. A Physiol. Pathol. Clin. Med. 54:98-102.

Umphrey, J. E., B. R. Moss, C. J. Wilcox, and H. H. Van Horn. 2001. Interrelationships in lactating Holsteins of rectal and skin temperatures, milk yield and composition, dry matter intake, body weight, and feed efficiency in summer in Alabama. J. Dairy Sci. 84:2680-2685.

USDA. 2002. Part I: Reference of Dairy Health and Management in the United States. USDA:APHIS:VS, IEAH, National Animal Health Monitoring System, Fort Collins, CO.

West, J. W. 2003. Effects of heat-stress on production in dairy cattle. J. Dairy Sci. 86:2131-2144.

Wolfenson, D., I. Flamenbaum, and A. Berman. 1988. Dry period heat stress relief effects on prepartum progesterone, calf birth weight, and milk production. J. Dairy Sci. 71:809-818.

Wolfenson, D., W. W. Thatcher, L. Badinga, J. D. Savio, R. Meidan, B. J. Lew, R. Braw-Tal, and A. Berman. 1995. Effect of heat stress on follicular development during the estrous cycle in lactating dairy cattle. Biol. Reprod. 52:1106-1113. 